\title{
Feedbacks between earlywood anatomy and non-structural carbohydrates affect spring phenology and wood production in ring-porous oaks
}

\author{
Gonzalo Pérez-de-Lis ${ }^{1}$, Ignacio García-González ${ }^{1}$, Vicente Rozas ${ }^{2}$, and José Miguel Olano ${ }^{2}$ \\ ${ }^{1}$ Departamento de Botánica, Universidade de Santiago de Compostela, EPS, 27002 Lugo, Spain \\ ${ }^{2}$ Área de Botánica, EUI Agrarias, Universidad de Valladolid, 42004 Soria, Spain
}

Correspondence to: Gonzalo Pérez-de-Lis (gonzalo.perezdelis@usc.es)

Received: 25 May 2016 - Published in Biogeosciences Discuss.: 26 May 2016

Revised: 7 September 2016 - Accepted: 16 September 2016 - Published: 5 October 2016

\begin{abstract}
Non-structural carbohydrates (NSC) play a central role in the construction and maintenance of a tree's vascular system, but feedbacks between the NSC status of trees and wood formation are not fully understood. We aimed to evaluate multiple dependencies among wood anatomy, winter NSC, and phenology for coexisting temperate (Quercus robur) and sub-Mediterranean (Q. pyrenaica) oaks along a water-availability gradient in the NW Iberian Peninsula. Sapwood NSC concentrations were quantified at three sites in December $2012(N=240)$. Leaf phenology and wood anatomy were surveyed in 2013. Structural equation modelling was used to analyse the interplay among hydraulic diameter $\left(D_{\mathrm{h}}\right)$, winter NSC, budburst date, and earlywood vessel production (EVP), while the effect of $D_{\mathrm{h}}$ and EVP on latewood width was assessed by using a mixed-effects model. NSC and wood production increased under drier conditions for both species. $Q$. robur showed a narrower $D_{\mathrm{h}}$ and lower soluble sugar (SS) concentration (3.88-5.08\% dry matter) than $Q$. pyrenaica $(4.06-5.57 \%$ dry matter), but $Q$. robur exhibited larger EVP and wider latewood $(1403 \mu \mathrm{m})$ than $Q$. pyrenaica $(667 \mu \mathrm{m})$. Stem diameter and $D_{\mathrm{h}}$ had a positive effect on SS concentrations, which were related to an earlier leaf flushing in both species. Sapwood sugar content appeared to limit EVP exclusively in $Q$. pyrenaica. In turn, $D_{\mathrm{h}}$ and EVP were found to be key predictors of latewood growth. Our results confirm that sapwood SS concentrations are involved in modulating growth resumption and xylem production in spring. $Q$. pyrenaica exhibited a tighter control of carbohydrate allocation to wood formation than $Q$. robur, which
\end{abstract}

would play a role in protecting against environmental stress in the sub-Mediterranean area.

\section{Introduction}

Non-structural carbohydrates (NSC) have multiple key functions in trees, such as maintenance respiration, osmoregulation, cryoprotection, or growth control (Morin et al., 2007; Sala et al., 2012; Wang and Ruan, 2013; Deslauriers et al., 2014). The asynchrony between carbon assimilation and consumption is solved by the active accumulation of NSC (Chapin et al., 1990; Dietze et al., 2014), which are mostly stored in stem, branches, and coarse roots as soluble sugars (SS) and starch (Salomon et al., 2016). A large part of the NSC budget of the tree is invested in construction and maintenance of the vascular system, as well as in turnover of fine roots and crown development (Wang and Ruan, 2013; DeSoto et al., 2016). The hydraulic network in ring-porous oaks is highly vulnerable to dysfunction due to cavitation of their large vessels, which operate at a narrow safety margin (Delzon and Cochard, 2014; Urli et al., 2015). The refilling of embolized vessels needs restoration of osmotic gradients by releasing SS into the conduits (Salleo et al., 2009; Brodersen and McElrone, 2013). Alternatively, the hydraulic function can be recovered through the formation of new conduits in the following spring (Brodribb et al., 2010). In ring-porous species, earlywood vessels are generally functional during only 1 year (Urli et al., 2015), and cambial resumption precedes leaf formation (Pérez-de-Lis et al., 2016). Stored NSC 
are therefore needed to provide energy and materials for leaf expansion and cambial activity at the onset of the growing season (El Zein et al., 2011).

Large vessels are presumed to boost carbon gain because stomatal conductance increases with the hydraulic capacity (Fichot et al., 2009). Concurrently, more carbohydrates may be allotted to hydraulic purposes in trees with wider but more vulnerable vessels (Salleo et al., 2009; Brodersen and McElrone, 2013). However, little is known about feedbacks between wood anatomy and short-distance NSC mobilization, which are probably influenced by tree vigour. Large, dominant trees commonly exhibit higher NSC levels and a faster NSC turnover (Sala and Hoch, 2009; Carbone et al., 2013; DeSoto et al., 2016), as well as wider vessels at the tree base to compensate for height-related hydraulic resistance in the stem (Petit et al., 2008). In turn, entangled relationships between tree vigour and growth are influenced by the timing of tree phenology, given that dominant trees show larger growing periods and more intense cambial activity (Rathgeber et al., 2011). Although the break in dormancy is mostly controlled by temperature and photoperiod (Basler and Körner, 2014), some studies suggest that high NSC concentrations in developing buds speed up leaf-out dates (Maurel et al., 2004). In winter, phloem of deciduous trees is probably nonfunctional, whereby sapwood might be involved in carbon translocation through the plant (Lacointe et al., 2004). The influx of sucrose from xylem conduits in branches into the buds was reported to be tightly correlated to bud swelling rates (Bonhomme et al., 2010), whilst high sucrose concentrations in the stem of mutant poplars have been associated with an advanced budburst (Park et al., 2009). Cascade effects of leaf phenology on secondary growth would consequently be expected, given that leaf and cambial phenology are coordinated at the whole-tree level (Pérez-de-Lis et al., 2016). In ring-porous oaks, winter temperature has been reported to affect earlywood formation, which has been attributed to thermally induced changes in respiratory demands and NSC levels (Gea-Izquierdo et al., 2012). However, the interplay between NSC, phenology, and tree growth is poorly understood.

Ecological requirements modulating phenology are linked to functional species-specific strategies (Basler and Körner, 2014). This is the case of the ring-porous oaks Quercus robur L. and Q. pyrenaica Willd., which coexist in the NW Iberian Peninsula. The former is widespread in Europe, being abundant in areas with mild-oceanic climate. By contrast, $Q$. pyrenaica is dominant in various mountain ranges of the subMediterranean area, hence exhibiting multiple adaptations to cope with summer drought and winter frost, such as late flushing (Pérez-de-Lis et al., 2016). These differences could impact carbon metabolism and allocation to growth (Valladares et al., 2000; Piper, 2011; Guillemot et al., 2015), as well as the rate of developmental processes (Deslauriers et al., 2009), affecting the adaptive capacity to track rapid climate change (Jump and Peñuelas, 2005). Water shortage is
Table 1. Climatic information on the study sites in 2012 and 2013.

\begin{tabular}{lrrrrr}
\hline Site & $\begin{array}{r}P \\
(\mathrm{~mm})\end{array}$ & $\begin{array}{r}\text { Rainy } \\
\text { days }\end{array}$ & $\begin{array}{r}T_{\mathrm{m}} \\
\left({ }^{\circ} \mathrm{C}\right)\end{array}$ & $\begin{array}{r}T_{\max } \\
\left({ }^{\circ} \mathrm{C}\right)\end{array}$ & $\begin{array}{l}T_{\min } \\
\left({ }^{\circ} \mathrm{C}\right)\end{array}$ \\
\hline 2012 & & & & & \\
\hline Hyperhumid & 1346.8 & 210 & 11.7 & 16.4 & 7.8 \\
Humid & 858.3 & 169 & 10.4 & 14.9 & 7.1 \\
Subhumid & 555.0 & 172 & 12.4 & 16.8 & 8.5 \\
\hline 2013 & & & & & \\
\hline Hyperhumid & 1979.0 & 225 & 11.6 & 15.8 & 8.0 \\
Humid & 1351.6 & 190 & 10.2 & 14.2 & 7.2 \\
Subhumid & 856.3 & 168 & 12.3 & 16.4 & 8.8 \\
\hline
\end{tabular}

$P$, mean precipitation; $T_{\mathrm{m}}$, mean temperature; $T_{\max }$, mean maximum temperature; $T_{\min }$, mean minimum temperature.

deemed to influence carbon metabolism in a complex manner by constraining the activity of both source and sink organs (Sala et al., 2012), and by changing sugar fractions (Deslauriers et al., 2014). While some studies have suggested that declining growth demand under drought causes NSC to be accumulated (Sala and Hoch, 2009; Lempereur et al., 2015; DeSoto et al., 2016), other authors have found a reduction in starch concentration under long-term drought (Rosas et al., 2013). Therefore, we need to understand how phenology and growth are coordinated with NSC in order to better predict plant responses to climate in the context of global warming.

In this research, data from stem sapwood NSC concentration in winter 2012, xylem anatomical traits, and leaf phenology in spring 2013 (as a proxy for cambial phenology) are used to disentangle the influence of their mutual interactions on the radial growth of ring-porous oaks growing along a water-availability gradient in the NW Iberian Peninsula. We focus on the possible differences in xylem anatomy and NSC levels between $Q$. robur and $Q$. pyrenaica along the gradient. In this regard, wood production and stem sapwood NSC concentration are expected to vary along the gradient, with reduced growth but increasing NSC storage under drier conditions. We also hypothesize that the more drought-tolerant $Q$. pyrenaica will have xylem growth that is more reduced than $Q$. robur but larger stem sapwood NSC concentrations. At the species level, we aim to test the following hypotheses: (i) stem diameter influences earlywood vessel size, which in turn affects NSC content in the stem; (ii) higher sapwood SS content in winter predisposes trees to advance growth resumption in spring, as well as to produce more earlywood vessels; and (iii) earlywood vessel number and size are key predictors of latewood growth in oaks. 

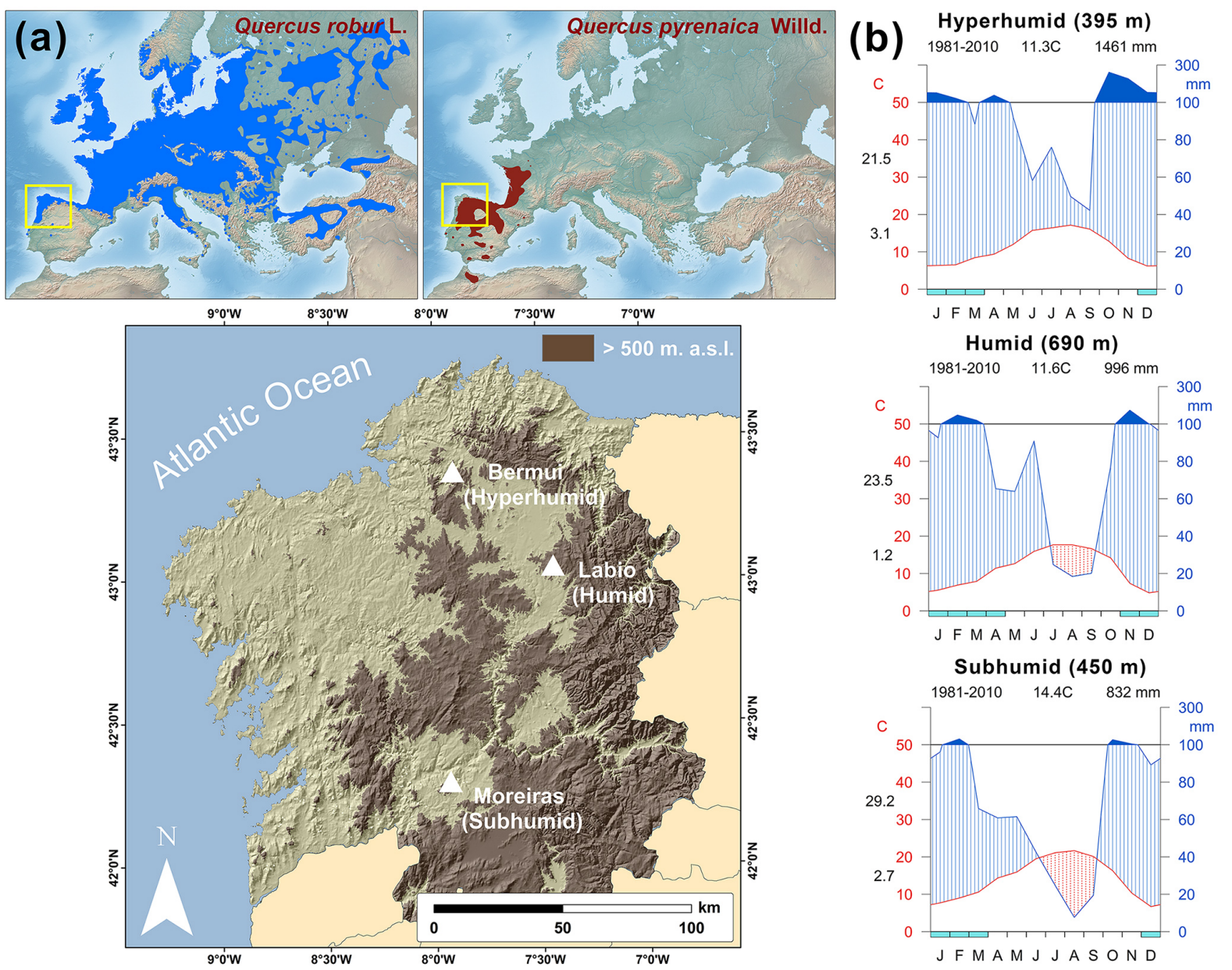

Figure 1. (a) Location of the study sites in the NW Iberian Peninsula and distribution range of Quercus robur and Q. pyrenaica (base map: http://www.euforgen.org). (b) Climatic diagrams of the sites including site altitude in ma.s.l, mean annual temperature, and total annual precipitation for the specified period.

\section{Materials and methods}

\subsection{Study sites}

The study area is located in the NW Iberian Peninsula, at the transition between the Atlantic and Mediterranean biogeographical regions (Fig. 1a). The experiment was conducted at three mixed stands of $Q$. robur (hereafter Qrob) and $Q$. pyrenaica (hereafter Qpyr) located along a north-tosouth transect of $120 \mathrm{~km}$, following a gradient of decreasing water supply (Fig. 1b). Annual rainfall declines from $1461 \mathrm{~mm}$ at the northernmost site Bermui (hyperhumid), to $996 \mathrm{~mm}$ at Labio (humid), and to $832 \mathrm{~mm}$ at the southernmost site Moreiras (subhumid). Mean annual temperature is lower at the hyperhumid $\left(11.3^{\circ} \mathrm{C}\right)$ and humid $\left(11.6^{\circ} \mathrm{C}\right)$ sites than at the subhumid site $\left(14.4^{\circ} \mathrm{C}\right)$. Sampled stands are dominated by $Q r o b$ at the hyperhumid and humid sites, whereas Qpyr is more frequent at the subhumid location. Forests at the hyperhumid and humid sites include temperate trees and understorey shrubs, such as Betula alba L., Castanea sativa Mill., Pyrus cordata Desy., Ilex aquifolium L., Daboecia cantabrica (Huds.) K. Koch, and Vaccinium myrtillus L. By contrast, thermophilic Mediterranean flora, such as $Q$. suber L., Laurus nobilis L., Arbutus unedo L., Osyris alba L., and Daphne gnidium L., dominates the subhumid location. Stand tree densities are 1178, 1082, and $530 \mathrm{ha}^{-1}$ at the hyperhumid, humid, and subhumid sites, respectively. Drought episodes can occur at the study region in summer, particularly at the subhumid site (Fig. 1b). Incident rainfall in 2012 was 8, 14, and $33 \%$ lower than the 1981-2010 average, at the hyperhumid, humid, and subhumid locations respectively, whereas it was 35,36 , and $3 \%$ higher than the average in 2013 (Table 1). However, in summer 2013, there were only $34(45 \mathrm{~mm}), 11(20 \mathrm{~mm})$, and $8(35 \mathrm{~mm})$ days of precipitation at the hyperhumid, humid and subhumid locations, respectively. Furthermore, mean maximum temperature was $22.0^{\circ} \mathrm{C}$ for the same period at the hyperhumid and humid sites but $25.3^{\circ} \mathrm{C}$ at the subhumid location. 


\subsection{Phenology and NSC concentration}

At each study site, 40 trees per species were randomly selected from those belonging to the dominant and intermediate crown classes (overall $N=240$ ), while highly suppressed and juvenile individuals were disregarded. In October 2012, we measured stem diameter from all selected individuals with a diameter tape, while tree height was estimated with a Blume-Leiss hypsometer. Leaf phenology was weekly monitored during 2013 using binoculars $(10 \times)$ at ca. $10 \mathrm{~m}$ distance from the stem. For each tree, budburst was identified as the day of year (DOY) in which the apical buds on the uppermost part of the crown were green and expanding, but no leaves were distinguishable yet. We considered budburst to be an indicator for cambial resumption in the stem, according to the high correlations observed between these two events in our study sites (Pérez-de-Lis et al., 2016). In late autumn, leaf shedding was identified as the date in which at least $50 \%$ of the leaves were shed from the crown. In addition, foliage density was visually estimated in July 2013 by counting the proportion of gaps in the crown and was expressed as a percentage of the theoretical maximum foliage density.

In order to analyse feedbacks between NSC and xylem anatomy, we quantified the content of NSC in sapwood by sampling one $5 \mathrm{~mm}$ diameter wood core per tree with an increment borer at breast height. Cores were taken in midDecember 2012, soon after the completion of leaf abscission, which occurred between mid- and late November for both species. After extraction, cores were immediately placed into a cool box, and subsequently stored at $-20^{\circ} \mathrm{C}$ to prevent carbohydrate degradation. Before NSC extraction, we identified the boundary between sapwood (pale-coloured) and heartwood (brown-coloured). Bark and traces of heartwood were removed, and the cores were oven-dried at $60^{\circ} \mathrm{C}$ for $72 \mathrm{~h}$. Sapwood was then finely grounded with a mixer mill (Retsch MM 400, Düsseldorf, Germany). We quantified NSC concentration for the whole sapwood by using the anthrone method (Olano et al., 2006). SS were extracted from $20 \mathrm{mg}$ of dry mass in $1 \mathrm{~mL}$ of ethanol $(80 \%)$ at $80^{\circ} \mathrm{C}$ for $30 \mathrm{~min}$. The extract was centrifuged for $10 \mathrm{~min}$ at $4000 \mathrm{rpm}$, and the supernatant was collected for the spectrophotometrical determination of SS concentrations, for which we used the anthrone reagent. Starch contained in the residue was hydrolysed with $1 \mathrm{~mL}$ of perchloric acid (35\%) for $1 \mathrm{~h}$, and determination was conducted by using the anthrone reagent, as previously described for SS. Total NSC, SS, and starch concentrations were expressed as a percentage of dry matter.

\subsection{Wood anatomical measurements}

In October 2013, one additional core was collected from all the selected trees to perform wood anatomical measurements. Cores were air-dried and mounted on wooden supports to be cut using a microtome (WSL Core Micro-

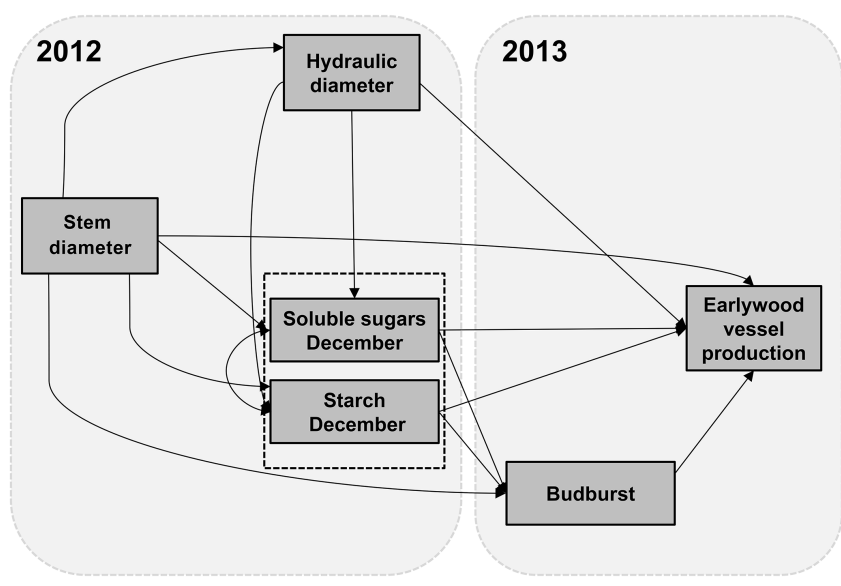

Figure 2. Structure of the hypothetical conceptual model showing interactions among stem diameter, hydraulic diameter in 2012, soluble sugars and starch concentrations in December 2012, and budburst date and earlywood vessel production in 2013 .

tome, Zurich, $\mathrm{CH}$ ) and polished. Cross-sectional surfaces were photographed with a digital camera (Canon EOS 600D, Tokyo, Japan) attached to a transmitted light microscope (Olympus BX40, Tokyo, Japan). Image analysis was applied on the rings formed in 2012 and 2013 using ImageJ 1.48v (Schneider et al., 2012) in order to quantify the lumen area of earlywood vessels, latewood width, and the number of earlywood vessels, which is a proxy of earlywood vessel production (EVP). For each vessel, we estimated the diameter of the equivalent circle, obtaining the hydraulic diameter $\left(D_{\mathrm{h}}\right)$ at the tree level according to the following equation:

$D_{\mathrm{h}}=\frac{\sum_{n=1}^{N} d_{n}^{5}}{\sum_{n=1}^{N} d_{n}^{4}}$

where $d_{n}$ is the diameter of the $n$ vessel (Sperry et al., 1994). According to the Hagen-Poiseuille equation, $D_{\mathrm{h}}$ is proportional to the hydraulic capacity.

\subsection{Comparisons along the gradient}

Variation among sites and between species for NSC, dates of budburst and leaf shedding, wood anatomical traits, and foliage density were evaluated by applying generalized linear models (GLMs) for gamma-distributed data. Multiple pairwise comparisons were also assessed to test differences among site factor levels. This analysis was performed by using the packages "Ime4" and "multcomp" for R 3.1.1 (R Core Team, 2014). Moreover, we calculated Pearson's correlation between stem diameter and tree height (one-tailed test of significance and $95 \%$ confidence interval). 


\subsection{Connections among earlywood anatomy, sapwood NSC content, and spring phenology}

We performed structural equation models (SEMs) to disentangle the role of winter NSC content as a possible regulator of budburst and EVP in 2013 at the species level. Thereby, data from all sites were pooled, and a unique model was fitted for each species. An SEM approach provides an adequate representation for interacting systems, in which simultaneous influences and responses, including direct and indirect effects, are explored (Grace, 2006). The structure of a hypothetical SEM, and its calculation, requires incorporating available a priori knowledge. According to the lines of evidence showed in the introduction, we hypothesized that larger trees show higher SS and starch concentrations due to their larger $D_{\mathrm{h}}$ (Fig. 2). In turn, high SS and starch concentrations in winter are expected to speed up tree phenology (budburst date) and boost EVP during the following year.

Standardized coefficients were estimated by the maximum likelihood method, and model evaluation was performed using a $\chi^{2}$ test. A $P$ value below 0.05 indicates that discrepancy between observed and expected covariance matrices is acceptable. The adjusted goodness of model fit index (AGFI) and the root mean square error of approximation (RMSEA) were complementarily performed in order to consider the effect of sample size on the model fit evaluation. Values of AGFI above 0.90 and RMSEA below 0.05 indicate an acceptable fit of the model in relation to the degrees of freedom. A $\chi^{2}$ test for multi-group invariance was applied to evaluate differences between the models fitted for each species. SEM analyses were carried out with AMOS 18.0 software (AMOS Development Corp., Mount Pleasant, South Carolina, USA).

\subsection{Predictors of latewood formation}

We performed generalized linear mixed-effects models (GLMMs) to identify how earlywood anatomy, foliage density, phenology, and winter NSC levels affected latewood production in 2013. The effect of site was included as a random component, while winter NSC, earlywood anatomy $\left(D_{\mathrm{h}}\right.$ and EVP in 2013), growing season length, and foliage density were the explanatory variables of the model. Collinearity was surveyed by calculating the generalized varianceinflation factors for each species. GLMMs were fitted by a log-link function with a gamma distribution, being ranked according to the corrected Akaike's information criterion (AICc; Bolker et al., 2009). We averaged the $95 \%$ confidence set of models according to the Akaike's weights, and the relative importance of a given variable was calculated as the sum of the weights across all models in which it was contained (Burnham and Anderson, 2002). Marginal (fixed effects only) and conditional $R^{2}$ (both fixed and random effects) were calculated by using the variance components of fixed and random factors and the residuals. The proportion change in variance (PCV) was quantified to provide the vari-

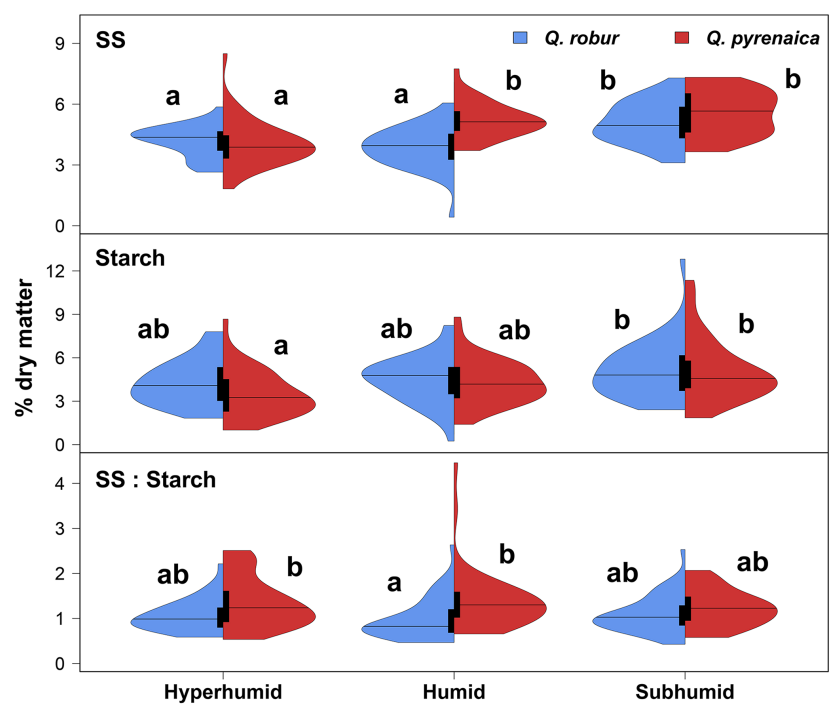

Figure 3. Distribution of soluble sugars (SS), starch concentrations, and SS-to-starch ratio, for Quercus robur $(N=120)$ and $Q$. pyrenaica $(N=120)$ at the three study sites. Horizontal lines represent the median, and black box plots show the extent of 25th and 75th percentiles. Lower-case letters indicate statistically significant differences along the gradient according to multiple pairwise comparisons. Note that different scales are used on the $y$ axis for each set of distributions.

ability in latewood width explained by the full model (containing fixed and random effects), as compared to the null model (only containing the random component). Complementarily, we estimated the percentage of the variance explained by each fixed factor, and both full and null models were ranked according to the minimum AICc and Bayesian information criterion (BIC) scores. Variance partitioning, $R^{2}$ and PCV calculations were performed by following the methods reported by Nakagawa and Schielzeth (2013). We used the packages "Ime4" and "MuMIn" for R 3.1.1 (R Core Team, 2014) to assess GLMM estimates, variance partitioning, and statistics.

\section{Results}

\subsection{Variation in NSC, wood anatomy, and leaf phenology along the gradient}

Mean SS concentrations along the gradient ranged from 3.88 to $5.08 \%$ dry matter in $Q r o b$ and from 4.06 to $5.57 \%$ dry matter in $Q p y r$, being similar to those of starch, which ranged from 4.28 to $5.11 \%$ dry matter in $Q r o b$ and from 3.47 to $5.11 \%$ in $Q p y r$ (Fig. 3). As a result, Qpyr exhibited greater SS concentrations than $\operatorname{Rrob}\left(F_{[1,238]}=18.27, P<0.001\right)$, while both starch and NSC levels did not differ between species ( $\operatorname{starch} F_{[1,238]}=2.14$, NSC $F_{[1,238]}=0.62$, $P>0.050)$. Such a pattern resulted in a higher SS-to-starch ratio for $Q p y r$ than for $Q r o b(F=18.07, P<0.001)$, espe- 

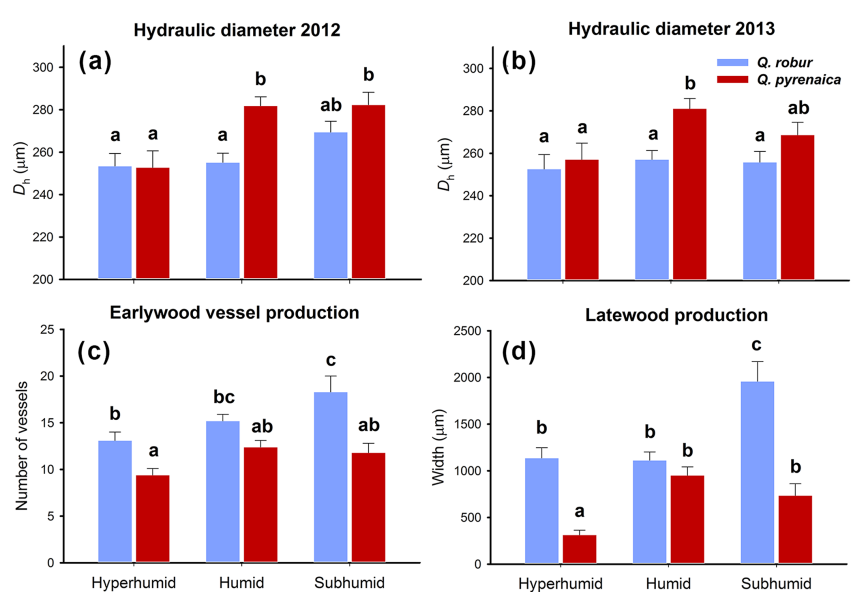

Figure 4. Mean values and SE of (a) hydraulic diameter in 2012, (b) hydraulic diameter in 2013, (c) earlywood vessel production, and (d) latewood production in 2013 for Quercus robur $(N=120)$ and $Q$. pyrenaica $(N=120)$. Lower-case letters indicate statistically significant differences along the gradient according to multiple pairwise comparisons.

cially at the humid location (Fig. 3), although there was no variation along the gradient $(F=0.21, P=0.814)$. In contrast, SS content decreased in both species from the subhumid to the hyperhumid site $\left(\operatorname{Qrob}_{[2,117]}=17.72\right.$, Qpyr $\left.F_{[2,117]}=21.89, P<0.001\right)$. The subhumid site exhibited a higher starch content than the hyperhumid location for $Q p y r$ $\left(F_{[2,117]}=8.59, P<0.001\right)$, whereas no clear pattern was found for $\operatorname{Qrob}\left(F_{[2,117]}=2.52, P=0.085\right)$.

Overall, Qpyr exhibited a higher $D_{\mathrm{h}}$ than Qrob (2012 $F_{[1,236]}=7.76,2013 \quad F_{[1,236]}=8.31, P<0.010$; Fig. 4a). The highest $D_{\mathrm{h}}$ values were found for $Q p y r$ at the humid (both years) and subhumid sites (2012), while Qrob had a more reduced variation along the gradient (2012 $F_{[2,117]}=2.89,2013 \quad F_{[2,117]}=0.18, P>0.050$; Fig. 4b). EVP and latewood width were higher in $Q r o b$ than in $Q p y r$ at the hyperhumid and subhumid sites, whereas differences were non-significant at the humid location (Fig. 4c, d). Trees at the subhumid site exhibited wider latewood (both species) and higher EVP (Qrob) than those at the hyperhumid location (Fig. 4c, d).

Qrob had a larger stem diameter than Qpyr at the hyperhumid site, whereas similar values were found at the humid and subhumid locations (Fig. 5a). Stem diameter was positively correlated with tree height in $\operatorname{Qrob}\left(r_{[118]}=0.60\right.$, $P<0.001)$ and $\operatorname{Qpyr}\left(r_{[118]}=0.58, P<0.001\right)$. Trees of both species were taller at the hyperhumid and subhumid sites than at the humid location ( $Q r o b \quad F_{[2,117]}=22.85$, Qpyr $\left.F_{[2,117]}=29.46, P<0.001\right)$. Qrob exhibited an earlier budburst than $Q p y r\left(F_{[1,236]}=527.83, P<0.001\right)$, occurring from early March to late April for the former and from midApril to late May for the latter. In both species, budburst occurred earlier at the subhumid site than at humid and hyper-
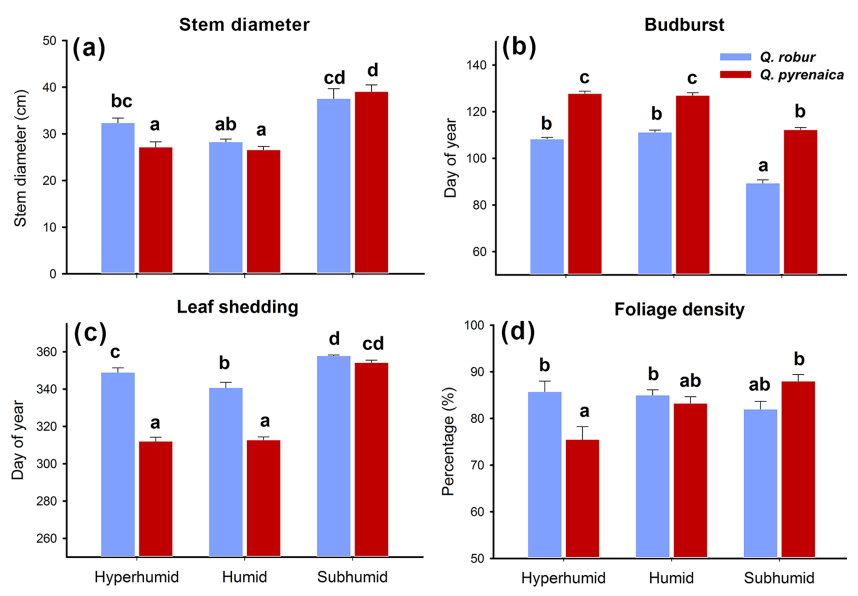

Figure 5. Mean values and SE of (a) stem diameter, (b) budburst date, (c) date of leaf shedding, and (d) foliage density in 2013 for Quercus robur $(N=120)$ and $Q$. pyrenaica $(N=120)$. Lower-case letters indicate statistically significant differences along the gradient according to multiple pairwise comparisons.

humid locations (Fig. 5b). By contrast, leaf shedding was first recorded at the hyperhumid and humid sites for Qpyr (DOY 312 on average; Fig. 5c), whereas some green leaves could be perceived until late December at the subhumid site ( $Q r o b$ DOY 357, Qpyr DOY 354). The leaf period was on average 42 days longer for $Q r o b$ than for $\operatorname{Qpyr}\left(F_{[1,236]}=450.90\right.$, $P<0.001)$ in 2013. Foliage density was similar along the gradient for $Q r o b$, but significantly lower at the hyperhumid site for $Q p y r$ (Fig. 5d). It is also relevant that numerous $Q p y r$ trees at the hyperhumid site had their leaves infected with powdery mildew in spring 2013.

\subsection{Species-specific models on functional relationships affecting wood production}

SEMs showed a good fit for both species ( $Q$ rob, $\chi_{[1, N=120]}^{2}=0.202, P=0.653 ;$ Qpyr,$\quad \chi_{[1, N=120]}^{2}=0.118$, $P=0.732$ ), with AGFI $>0.90$ and RMSEA $<0.1$ (Fig. 6a, b). Stem diameter had a positive indirect effect on SS levels that was mediated by $D_{\mathrm{h}}$ in 2012. Large trees exhibited an earlier budburst date, partially related to their higher SS concentrations in winter. In Qrob, SS content affected EVP by mediating budburst date, although our model explained a low amount of the observed variability in EVP (Fig. 6a). In Qpyr, SS concentrations had a positive direct effect on EVP, with an acceptable $R^{2}$ value for EVP $\left(R^{2}=0.20\right.$; Fig. $\left.6 \mathrm{~b}\right)$. Neither EVP nor budburst date responded to winter starch concentration, although our model failed to account for the observed variability in the latter variable.

Our GLMM had a sufficiently good performance $\left(R_{\text {[conditional] }}^{2}>36 \%\right)$. The fixed factors explained most of the variability in latewood width $\left(R_{\text {[marginal] }}^{2}>34 \%\right)$, while considerably high PCV values confirmed the better fit of the full 
Table 2. Statistics of the null and full generalized linear models for Quercus robur (left) and Q.pyrenaica (right).

\begin{tabular}{|c|c|c|c|c|c|c|}
\hline & \multicolumn{3}{|c|}{$Q . \operatorname{robur}(N=120)$} & \multicolumn{3}{|c|}{$Q$. pyrenaica $(N=120)$} \\
\hline & Null model & Full model & $\operatorname{PVE}(\%)$ & Null model & Full model & $\operatorname{PVE}(\%)$ \\
\hline \multicolumn{7}{|l|}{ Fixed effects } \\
\hline Intercept & $7.209^{* * *}$ & $4.348^{* * *}$ & & $6.404^{* * *}$ & $2.696 * *$ & \\
\hline $\mathrm{GS}_{13}$ & & 0.003 & 4.84 & & 0.003 & 5.22 \\
\hline $\mathrm{NSC}_{12}$ & & -0.022 & 1.06 & & 0.003 & 5.81 \\
\hline$D_{\mathrm{h} 13}$ & & $0.004^{*}$ & 8.26 & & $0.005^{* *}$ & 16.64 \\
\hline $\mathrm{EVP}_{13}$ & & $0.050^{* * *}$ & 83.37 & & $0.092^{* * *}$ & 69.03 \\
\hline $\mathrm{FD}_{13}$ & & 0.006 & 2.47 & & 0.008 & 3.31 \\
\hline \multicolumn{7}{|c|}{ Variance components } \\
\hline Site & 0.033 & 0.013 & & 0.183 & 0.060 & \\
\hline Residuals & 0.380 & 0.332 & & 0.829 & 0.605 & \\
\hline Fixed effects & & 0.181 & & & 0.363 & \\
\hline $\mathrm{PCV}_{[\text {site }]}$ & & $83.79 \%$ & & & $89.18 \%$ & \\
\hline $\mathrm{PCV}_{\text {[residuals] }}$ & & $26.81 \%$ & & & $28.30 \%$ & \\
\hline$R_{\mathrm{GLMM}_{(\mathrm{m})}}^{2}$ & & $34.42 \%$ & & & $35.28 \%$ & \\
\hline$R_{\mathrm{GLMM}_{(\mathrm{c})}}^{2}$ & & $36.95 \%$ & & & $41.14 \%$ & \\
\hline - log likelihood & 968.20 & 946.44 & & 889.84 & 865.13 & \\
\hline $\mathrm{AIC}$ & 1942.41 & 1908.89 & & 1785.67 & 1746.25 & \\
\hline $\mathrm{AICc}$ & 1942.62 & 1910.19 & & 1785.88 & 1747.55 & \\
\hline $\mathrm{BIC}$ & 1950.77 & 1931.19 & & 1794.03 & 1768.55 & \\
\hline
\end{tabular}

$N$, sample size for each species. PVE, relative proportion of variance explained by each fixed factor. $\mathrm{GS}_{13}$, length of the growing season in 2013. NSC 12 , total non-structural carbohydrates in December 2012. $D_{\mathrm{h} 13}$, hydraulic diameter in $2013 . \mathrm{EVP}_{13}$, earlywood vessel production in 2013. $\mathrm{FD}_{13}$, foliage density in 2013. PCV, proportion change in variance. $R_{\mathrm{GLMM}}^{2}$, marginal coefficient of determination.

$R_{\mathrm{GLMM}}^{2}$ (c) , conditional coefficient of determination. AIC, Akaike's information criterion. AICc, corrected Akaike's information criterion. BIC, Sawa's Bayesian information criterion. ${ }^{* * *} P \leq 0.001$; ${ }^{* *} P \leq 0.01$; $^{*} P \leq 0.05$.

model with respect to the null one. A similar result was obtained after ranking the models according to their AICc, log likelihood, and BIC scores (Table 2). Larger and more numerous earlywood vessels strongly favoured latewood production (Table 2). In fact, EVP and $D_{\mathrm{h}}$ were the most relevant predictors, attaining a relative influence above $85 \%$ (Fig. 7). However, EVP accounted for 69 (83) \% of the variability in latewood width predicted by the fixed part of the model for Qpyr (Qrob), whereas $D_{\mathrm{h}}$ only explained 8-16\% (Table 2). Variables related to tree vigour were less relevant, such as foliage density (40-60\%) and length of the growing season (31-40\%), with no significant effects on latewood width (Table 2). Winter NSC only accounted for a marginal weight in both species, having a negative slope for Qrob but positive for Qpyr (Table 2, Fig. 7). Problems of collinearity were not detected among the predictors included in the model (Supplement, Table S1).

\section{Discussion}

\subsection{NSC allocation to xylem growth reflects contrasting stress-tolerance strategies in oaks}

According to our expectations, sapwood SS content decreased from the subhumid to the hyperhumid site for both species, and starch content followed a similar pattern for $Q$ pyr. More immediate effects of water shortage on stem growth than on photosynthesis likely favoured carbohydrate accumulation in the previous summer (Sala et al., 2012; Lempereur et al., 2015; DeSoto et al., 2016). Such a response should be adaptive in dry environments because sugars contribute to prevent desiccation through osmotic regulation and cavitation repair (Salleo et al., 2009; Brodersen and McElrone, 2013; Pantin et al., 2013; Deslauriers et al., 2014). The fact that $Q p y r$ showed larger vessels at the humid and subhumid locations cannot be explained by corresponding differences in tree height, whereby long-distance water transport was probably prompted under drier conditions, which concurrently increased the risk of vessel dysfunction (Urli et al., 2015). Although the prevalence of vessel refilling is still under discussion (Delzon and Cochard, 2014), we hypothesize 
(a)

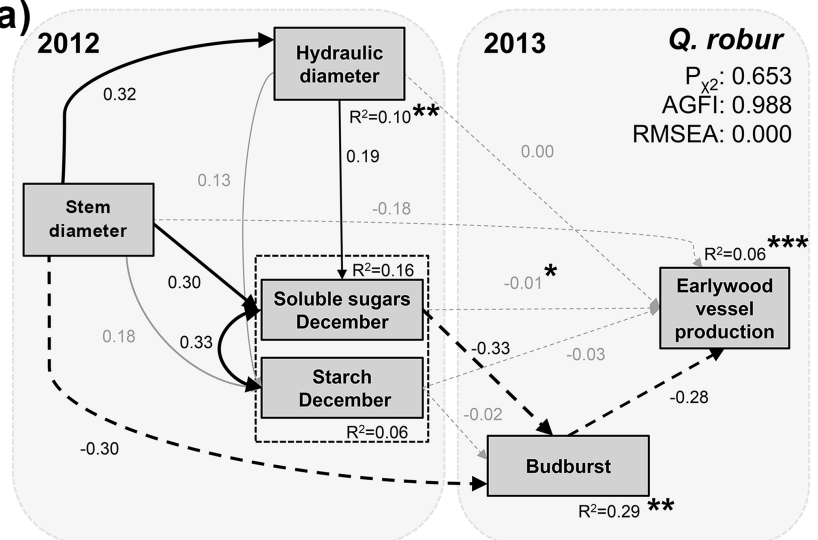

(b)

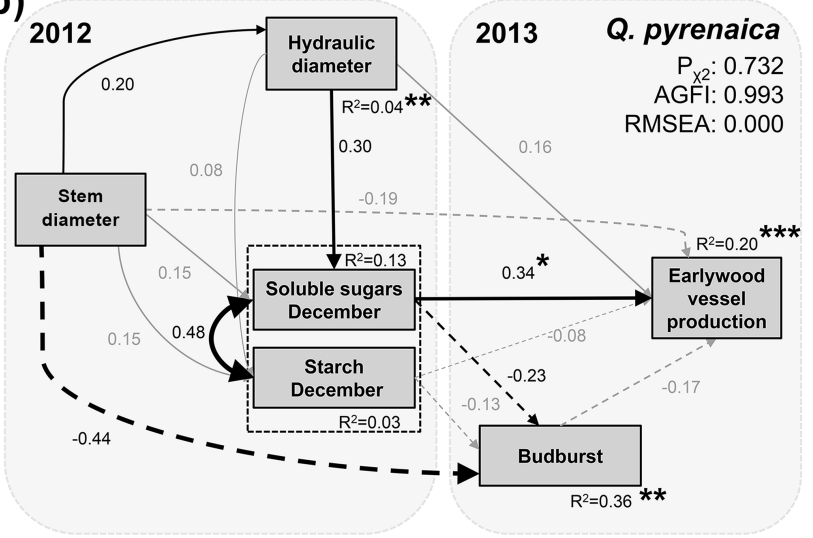

Figure 6. Structural equation models fitted for (a) Quercus robur $(N=120)$ and (b) $Q$. pyrenaica $(N=120)$. Variables of the conceptual model are stem diameter, hydraulic diameter in 2012, soluble sugars and starch concentrations in December 2012, budburst date, and earlywood vessel production (number of vessels) in 2013. Explained deviances of endogenous variables are shown near the boxes. Solid black (positive effects) and dashed (negative effects) arrows denote significant relations, while non-significant relations are shown as grey coefficients and arrows. The $\chi^{2}$ test, the adjusted goodness of model fit index (AGFI), and the root mean square error of approximation (RMSEA) are shown for each model. Asterisks indicate paths or error values significantly different between the models of both species. ${ }^{* * *} P \leq 0.001,{ }^{* *} P \leq 0.01$, and * $P \leq 0.05$.

that enhanced SS concentration might be involved in compensating hydraulic vulnerability in this species.

Wood formation declined along with NSC content from the subhumid toward the hyperhumid site, which contradicts our expectations, and also a possible trade-off between NSC accumulation and growth. A shorter growing season at the hyperhumid and humid locations could restrict photosynthesis (Morecroft et al., 2003), as well as xylem formation (Rathgeber et al., 2011). A lower tree density at the subhumid site might be associated with a reduced intertree competition, which is assumed to favour both carbon uptake and xylem growth (Fernández-de-Uña et al., 2016).

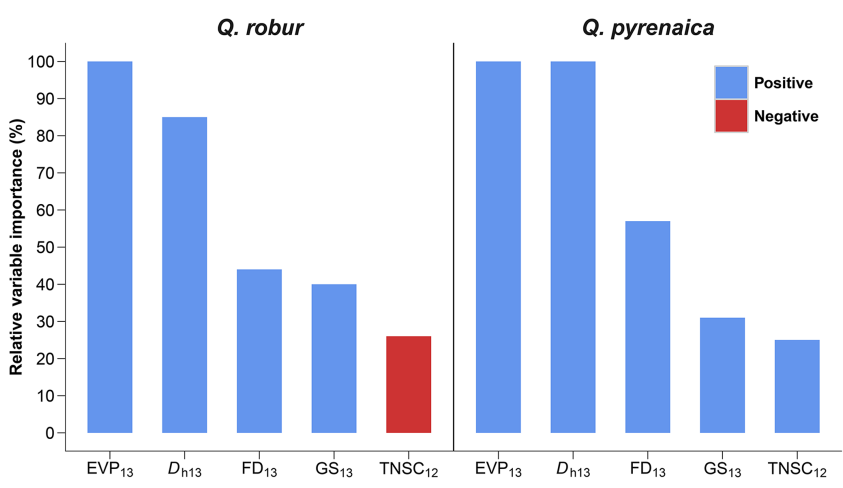

Figure 7. Relative importance of the variables driving latewood production in 2013, expressed as a percentage, for Quercus robur $(N=120)$ and $Q$. pyrenaica $(N=120)$. Site effect was included as a random factor in the model. $\mathrm{NSC}_{12}$ are total non-structural carbohydrates in December 2012, $D_{\mathrm{h} 13}$ is hydraulic diameter in 2013 , EVP $_{13}$ is earlywood vessel production in $2013, \mathrm{GS}_{13}$ is length of the growing season in 2013 , and $\mathrm{FD}_{13}$ is foliage density in 2013. Different colours of bars denote variables with either a positive or negative effect.

Strong differences between the two Atlantic sites for Qpyr, however, contrasted with their similar tree density. Soil water excess in winter at the hyperhumid site could exacerbate carbon consumption associated with fermentation processes and root anaerobic stress (Ferner et al., 2012). Moreover, Qpyr trees exhibited sparser foliage and more severe powdery mildew infestation at the hyperhumid site, which may reduce NSC levels and growth (Améglio et al., 2001; Martínez-Vilalta, 2014; Camarero et al., 2016). Growth decline and tree dieback were indeed recently reported for oaks suffering from both high competition levels and water excess after extremely rainy periods (Rozas and García-González, 2012).

The sub-Mediterranean Qpyr exhibited a higher SS-tostarch ratio at the onset of dormancy than the temperate $Q r o b$, although NSC content was similar for both species. Sugars play a key role in the osmotic protection against freezing damage (Améglio et al., 2004), whereby higher symplastic SS concentrations would reflect stronger cold tolerance (Morin et al., 2007), as is the case for Qpyr. On the other hand, EVP and latewood width were generally lower for $Q p y r$ than for Qrob, particularly under more Mediterranean climatic conditions. This contradictory outcome suggests that Qpyr is more conservative than Qrob in allocating NSC to wood production, hence reflecting a stronger drought tolerance (Valladares et al., 2000; Piper, 2011). Saving NSC may allow long-lived trees to mitigate detrimental effects of eventual wildfire and drought episodes (Sala et al., 2012), which are frequent at the Mediterranean area (Rosas et al., 2013; Camarero et al., 2016). However, such a strategy could entail a high opportunity cost under favourable conditions (Chapin et al., 1990). Therefore, Qrob probably out- 
competed Qpyr in our study sites, demonstrating that temperate oaks are more competitive than sub-Mediterranean ones (Rodríguez-Calcerrada et al., 2008; Grossiord et al., 2014). However, validation of these hypotheses requires further research quantifying the whole-tree NSC pool size and the activity of complementary carbon sinks. In this regard, a recent study suggested that neighbouring Qpyr trees were able to share NSC through the root system, which is an important carbon reservoir within the tree (Salomon et al., 2016).

\subsection{Dependencies among NSC content, phenology, and earlywood vessels}

Our SEMs confirmed the hypothesized functional relationships among earlywood anatomy, spring phenology, and NSC content. The growing season started earlier in large trees, which is in line with previous studies analysing cambial activity (Rathgeber et al., 2011). Stem diameter also had a positive effect on SS content at dormancy, which was mediated by the hydraulic capacity (i.e. vessel size). Enhanced water transport capacity in trees with large vessels may boost carbohydrate uptake under a high evaporative demand (Meinzer et al., 2005; Fichot et al., 2009). Alternatively, since large vessels are thought to be more vulnerable to cavitation (Sperry et al., 1994), higher SS concentrations may be required in the sapwood of trees bearing wider vessels to maintain long-distance water transport (Brodersen and McElrone, 2013). Trees with a higher SS concentration in the stem showed earlier budburst in the following spring, as reported in poplar (Park et al., 2009). Bud swelling depends on sugar influx from sapwood vessels (Maurel et al., 2004; Bonhomme et al., 2010), which have been suggested to be responsible for carbohydrate transport during the dormant period (Lacointe et al., 2004). In addition, xylem sap osmolarity plays a role in the generation of the stem pressure needed to reverse winter embolisms in early spring (Améglio et al., 2001). A reduced ability to repair embolism in trees with low xylem sap SS concentration could thus negatively affect the supply of water to swelling buds (Améglio et al., 2001).

EVP was in tune with SS concentration for $Q p y r$, whereas this effect was irrelevant for Qrob. Such a discrepancy in the effect of stored carbohydrates on growth is consistent with the aforesaid carbon use strategies, and could reflect the contrasting stress tolerance of the study species (Guillemot et al., 2015). Our results consequently suggest that $Q p y r$ was able to limit construction costs in spring according to SS levels. Presumably, high overwintering SS levels in sapwood somehow increased energy and materials as well as water supplied to growing tissues in spring, even though starch mobilization may be initiated at that time (Améglio et al., 2001). Furthermore, sugars are elicitors of auxin biosynthesis and distribution (Lilley et al., 2012; Sairanen et al., 2012), as well as growth promoters (Stewart et al., 2011). Although relations between carbon accumulation and growth are com- plex, and mainly related to the activity of carbon sinks (Lempereur et al., 2015), a growing body of literature suggests that NSC availability is involved in growth regulation (Pantin et al., 2013; Dietze et al., 2014; Guillemot et al., 2015). This can be particularly true for earlywood given its reliance on stored carbohydrates (Skomarkova et al., 2006). This idea agrees with the direct association between tree vigour, NSC pool, and growth found in multiple species (Deslauriers et al., 2009; Carbone et al., 2013), as well as with the observed positive effect of $\mathrm{CO}_{2}$ fertilization on tree growth (Nissinen et al., 2016). EVP did not respond to sapwood starch content, which suggests that thermal-induced changes in starch breakdown during cold hardening could be more decisive than the total amount of reserves. This is consistent with the connection between earlywood anatomy and autumn-winter temperature reported by dendrochronological studies (GeaIzquierdo et al., 2012). However, the actual starch availability could be overestimated if starch contained in sapwood is partially inaccessible (Sala et al., 2012).

\subsection{Earlywood anatomy is a predictor of latewood growth}

The most influential predictors driving latewood growth did not differ between $Q r o b$ and $Q p y r$, suggesting common underlying mechanisms for both species. Latewood width was considerably influenced by earlywood properties within the same tree ring, whereas the effects of foliage density, length of the growing season, and winter NSC content were secondary. This result confirms the positive impact of enhanced water transport capacity on xylem formation (Fichot et al., 2009), which is largely related to both conduit size (Sperry et al., 1994) and total conductive area (Meinzer et al., 2005). A more efficient water supply to growing tissues probably allows trees to protect cambial activity against water shortage in summer (Wang and Ruan, 2013). Despite the higher construction costs, abundant earlywood vessels of distinct size could be useful to avoid hydraulic failure because functioning small conduits would serve as local water reservoirs to recover neighbouring collapsed ones (Brodersen and McElrone, 2013). Moreover, an efficient hydraulic network may enhance carbon gain under favourable conditions (Fichot et al., 2009), hence ensuring key processes in which sugars are involved, such as osmotic regulation (Sala et al., 2012; Deslauriers et al., 2014) and embolism repair (Salleo et al., 2009). Our results suggested that changes in cell division and differentiation rates are more relevant for wood production than the duration of the growing period, as has been previously reported for conifers (Rathgeber et al., 2011). Although defoliation is assumed to impair carbon gain and radial growth in evergreen (Rosas et al., 2013; Camarero et al., 2016) and deciduous species (Améglio et al., 2001), we found that foliage density had a minor effect on latewood growth, which may reflect the high overall foliage density levels at the study sites. 


\section{Conclusions}

In this study, non-structural carbohydrates in sapwood, wood anatomy, and leaf phenology were comprehensively addressed for two ring-porous species during a 1 year period, along a broad geographical range in the NW Iberian Peninsula. Our results reveal that feedbacks between earlywood vessels and soluble sugars involve changes in wood production. Earlywood vessel formation showed a tighter control by soluble sugar content in $Q$. pyrenaica than in $Q$. robur, suggesting a more conservative carbon use strategy for the former species. These lines of evidence support the idea that non-structural carbohydrates play a role in the acquisition of resistance to cope with harsh environmental conditions in the sub-Mediterranean area. We acknowledge the need for further research comprising a longer time span, soluble sugar fractioning, additional tree compartments such as branches and roots, and a comprehensive data set on cambial phenology instead of isolated leaf phenophases. However, this study suggests the existence of stable functional interactions between sapwood carbohydrate levels, xylem anatomy, and phenology in ring-porous oaks. In the light of our results, we suggest that $Q$. pyrenaica, and to a lesser extent $Q$. robur, could mitigate increasing hydraulic vulnerability under climate warming by prioritizing carbon accumulation over growth. Nevertheless, such a mechanism would impose additional limitations for secondary growth if adverse climate episodes become more frequent in future decades.

\section{Data availability}

Data used in this article are available in the Supplement.

\section{The Supplement related to this article is available online at doi:10.5194/bg-13-5499-2016-supplement.}

Author contributions. Ignacio García-González, José Miguel Olano, and Vicente Rozas conceived and designed the experiment. Ignacio García-González, Vicente Rozas, and Gonzalo Pérezde-Lis conducted fieldwork. Gonzalo Pérez-de-Lis performed sample processing and data collection. José Miguel Olano and Gonzalo Pérez-de-Lis executed model calculation. Gonzalo Pérezde-Lis prepared the manuscript. Ignacio García-González, José Miguel Olano, and Vicente Rozas provided editorial advice.

Acknowledgements. The authors are grateful to G. Juste and E. Marcos for laboratory technical assistance, to A. GarcíaCervigón for advice on SEMs, and to M. Souto and G. Guada for their contribution in sample collection. We also thank L. Costa and C. Franco from the Fragas do Eume Natural Park, Forest Service of Xunta de Galicia, and MVMC of Moreiras for facilitating fieldwork. This work was supported by the Spanish Ministry of Economy and Competitiveness (research projects BFU-21451 and CGL2012-34209) with European Regional Development Fund, and by Xunta de Galicia (research projects 10MDS291009PR and GRC2015/008). Gonzalo Pérez-de-Lis received a PhD FPU-ME grant (grant number AP2010-4911) funded by the Spanish Ministry of Education. The work was partially inspired within the FPS COST Action FP1106 - STReESS and Ecometas net CGL201453840REDT. The authors declare no conflict of interests of any kind.

Edited by: T. Keenan

Reviewed by: two anonymous referees

\section{References}

Améglio, T., Ewers, F. W., Cochard, H., Martignac, M., Vandame, M., Bodet, C., and Cruiziat, P.: Winter stem xylem pressure in walnut trees: effects of carbohydrates, cooling and freezing, Tree Physiol., 21, 387-394, 2001.

Améglio, T., Decourteix, M., Alves, G., Valentin, V., Sakr, S., Julien, J.-L., Petel, G., Guilliot, A., and Lacointe, A.: Temperature effects on xylem sap osmolarity in walnut trees: evidence for a vitalistic model of winter embolism repair, Tree Physiol., 24, 785-793, 2004.

Basler, D. and Körner, C.: Photoperiod and temperature responses of bud swelling and bud burst in four temperate forest tree species, Tree Physiol., 34, 377-388, 2014.

Bolker, B. M., Brooks, M. E., Clark, C. J., Geange, S. W., Poulsen, J. R., Stevens M. H. H., and White J.-S. S.: Generalized linear mixed models: a practical guide for ecology and evolution, Trends Ecol. Evol., 24, 127-135, 2009.

Bonhomme, M., Peuch, M., Améglio, T., Rageau, R., Guilliot, A., Decourteix, M., Alves, G., Sakr, S., and Lacointe, A.: Carbohydrate uptake from xylem vessels and its distribution among stem tissues and buds in walnut (Juglans regia L.), Tree Physiol., 30, 89-102, 2010.

Brodersen, C. R. and McElrone, A. J.: Maintenance of xylem network transport capacity: a review of embolism repair in vascular plants, Front. Plant Sci., 4, 108, doi:10.3389/fpls.2013.00108, 2013.

Brodribb, T. J., Bowman, D. J. M. S., Nichols, S., Delzon, S., and Burlett, R.: Xylem function and growth rate interact to determine recovery rates after exposure to extreme water deficit, New Phytol., 188, 533-542, 2010.

Burnham, K. P. and Anderson, D. R.: Model Selection and Multimodel Inference, Springer, Heidelberg, 2002.

Camarero, J. J., Sangüesa-Barreda, G., and Vergarechea, M.: Prior height, growth, and wood anatomy differently predispose to drought-induced dieback in two Mediterranean oak species, Ann. Forest Sci., 73, 341-351, 2016.

Carbone, M. S., Czimczik, C. I., Keenan, T. F., Murakami, P. F., Pederson, N., Schaberg, P. G., Xu, X., and Richardson, A. D.: Age, allocation and availability of nonstructural carbon in mature red maple trees, New Phytol., 200, 1145-1155, 2013.

Chapin, F. S., Schulze, E.-D., and Mooney, H. A.: The ecology and economics of storage in plants, Annu. Rev. Ecol. Syst., 21, 423447, 1990. 
Delzon, S. and Cochard, H.: Recent advances in tree hydraulics highlight the ecological significance of the hydraulic safety margin, New Phytol., 203, 355-358, 2014.

Deslauriers, A., Giovannelli, A., Rossi, S., Castro, G., Fragnelli, G., and Traversi, L.: Intra-annual cambial activity and carbon availability in stem of poplar, Tree Physiol., 29, 1223-1235, 2009.

Deslauriers, A., Beaulieu, M., Balducci, L., Giovannelli, A., Gagnon, M. J., and Rossi, S.: Impact of warming and drought on carbon balance related to wood formation in black spruce, Ann. Bot., 114, 335-345, 2014.

DeSoto, L., Olano, J. M., and Rozas, V.: Secondary Growth and Carbohydrate Storage Patterns Differ between Sexes in Juniperus thurifera, Front. Plant Sci., 7, 1-12, 2016.

Dietze, M. C., Sala, A., Carbone, M. S., Czimczik, C. I., Mantooth, J. A., Richardson, A. D., and Vargas, R.: Nonstructural carbon in woody plants, Annu. Rev. Plant Biol., 65, 667-687, 2014.

El Zein, R., Maillard, P., Bréda, N., Marchand, J., Montpied, P., and Gérant, D.: Seasonal changes of $\mathrm{C}$ and $\mathrm{N}$ non-structural compounds in the stem sapwood of adult sessile oak and beech trees, Tree Physiol., 31, 843-854, 2011.

Fernández-de-Uña, L., McDowell, N. G., Cañellas, I., and GeaIzquierdo, G.: Disentangling the effect of competition, $\mathrm{CO}_{2}$ and climate on intrinsic water-use efficiency and tree growth, J. Ecol., 104, 678-690, 2016.

Ferner, E., Rennenberg, H., and Kreuzwieser, J.: Effect of flooding on C metabolism of flood-tolerant (Quercus robur) and nontolerant (Fagus sylvatica) tree species, Tree Physiol., 32, 135145, 2012.

Fichot, R., Laurans, F., Monclus, R., Moreau, A., Pilate, G., and Brignolas, F.: Xylem anatomy correlates with gas exchange, water-use efficiency and growth performance under contrasting water regimes: evidence from Populus deltoides x Populus nigra hybrids, Tree Physiol., 29, 1537-1549, 2009.

Gea-Izquierdo, G., Fonti, P., Cherubini, P., Martín-Benito, D., Chaar, H., and Cañellas, I.: Xylem hydraulic adjustment and growth response of Quercus canariensis Willd. to climatic variability, Tree Physiol., 32, 401-413, 2012.

Grace, J. B.: Structural equation modeling and natural systems, Cambridge University Press, Cambridge, 2006.

Grossiord, C., Gessler, A., Granier, A., Pollastrini, M., Bussotti, F., and Bonal, D.: Interspecific competition influences the response of oak transpiration to increasing drought stress in a mixed Mediterranean forest, Forest Ecol. Manage., 318, 54-61, 2014.

Guillemot, J., Martin-StPaul, N. K., Dufrêne, E., François, C., Soudani, K., Ourcival, J. M., and Delpierre, N.: The dynamic of the annual carbon allocation to wood in European tree species is consistent with a combined source-sink limitation of growth: implications for modelling, Biogeosciences, 12, 2773-2790, doi:10.5194/bg-12-2773-2015, 2015.

Jump, A. S. and Peñuelas, J.: Running to stand still: Adaptation and the response of plants to rapid climate change, Ecol. Lett., 8, 1010-1020, 2005.

Lacointe, A., Deleens, E., Améglio, T., Saint-Joanis, B., Lelarge, C., Vandame, M., Song, G. C., and Daudet, F. A.: Testing the branch autonomy theory: $\mathrm{A}{ }^{13} \mathrm{C} /{ }^{14} \mathrm{C}$ double-labelling experiment on differentially shaded branches, Plant Cell Environ., 27, 1159-1168, 2004.
Lempereur, M, Martin-StPaul, N. K., Damesin, C., Joffre, R., Ourcival, J., Rocheteau, A., and Rambal, S.: Growth duration is a better predictor of stem increment than carbon supply in a Mediterranean oak forest: implications for assessing forest productivity under climate change, New Phytol., 207, 579-590, 2015.

Lilley, J. L. S., Gee, C. W., Sairanen, I., Ljung, K., and Nemhauser, J. L.: An endogenous carbon-sensing pathway triggers increased auxin flux and hypocotyl elongation, Plant Physiol., 160, 22612270, 2012.

Martínez-Vilalta, J.: Carbon storage in trees: pathogens have their say, Tree Physiol., 34, 215-217, 2014.

Maurel, K., Leite, G. B., Bonhomme, M., Guilliot, A., Rageau, R., Pétel, G., and Sakr, S.: Trophic control of bud break in peach (Prunus persica) trees: a possible role of hexoses, Tree Physiol., 24, 579-588, 2004.

Meinzer, F. C., Bond, B. J., Warren, J. M., and Woodruff, D. R.: Does water transport scale universally with tree size?, Funct. Ecol., 19, 558-565, 2005.

Morecroft, M. D., Stokes, V. J., and Morison, J. I. L.: Seasonal changes in the photosyntetic capacity of canopy oak (Quercus robur) leaves: the impact of slow development on annual carbon uptake, Int. J. Biometeorol., 47, 221-226, 2003.

Morin, X., Améglio, T., Ahas, R., Kurz-Besson, C., Lanta, V., Lebourgeois, F., Miglietta, F., and Chuine, I.: Variation in cold hardiness and carbohydrate concentration from dormancy induction to bud burst among provenances of three European oak species, Tree Physiol., 27, 817-825, 2007.

Nakagawa, S. and Schielzeth, H.: A general and simple method for obtaining $R^{2}$ from generalized linear mixed-effects models, Methods Ecol. Evol., 4, 133-142, 2013.

Nissinen, K., Nybakken, L., Virjamo, V., and Julkunen-Tiitto, R.: Slow-growing Salix repens (Salicaceae) benefits from changing climate, Environ. Exp. Bot., 128, 59-68, 2016.

Olano, J., Menges, E., and Martinez, E.: Carbohydrate storage in five resprouting Florida scrub plants across a fire chronosequence, New Phytol., 170, 99-105, 2006.

Pantin, F., Fanciullino, A.-L., Massonnet, C., Dauzat, M., Simonneau, T., and Muller, B.: Buffering growth variations against water deficits through timely carbon usage, Front. Plant Sci., 4, 483, doi:10.3389/fpls.2013.00483, 2013.

Park, J. Y., Canam, T., Kang, K. Y., Unda, F., and Mansfield, S. D.: Sucrose phosphate synthase expression influences poplar phenology, Tree Physiol., 29, 937-946, 2009.

Pérez-de-Lis, G., Rossi, S., Vázquez-Ruiz, R. A., Rozas, V., and García-González, I.: Do changes in spring phenology affect earlywood vessels? Perspective from the xylogenesis monitoring of two sympatric ring-porous oaks, New Phytol., 209, 521-530, 2016.

Petit, G., Anfodillo, T., and Mencuccini, M.: Tapering of xylem conduits and hydraulic limitations in sycamore (Acer pseudoplatanus) trees, New Phytol., 177, 653-664, 2008.

Piper, F. I.: Drought induces opposite changes in the concentration of non-structural carbohydrates of two evergreen Nothofagus species of differential drought resistance, Ann. For. Sci., 68, 415-424, 2011.

Rathgeber, C. B. K., Rossi, S., and Bontemps, J.-D.: Cambial activity related to tree size in a mature silver-fir plantation, Ann. Bot., 108, 429-438, 2011. 
R Core Team: A language and environment for statistical computing, R Foundation for Statistical Computing, Vienna, Austria, available at: http://www.R-project.org/, 2014.

Rodríguez-Calcerrada, J., Pardos, J. A., Gil, L., Reich, P. B., and Aranda, I.: Light response in seedlings of a temperate (Quercus petraea) and a sub-Mediterranean species (Quercus pyrenaica): Contrasting ecological strategies as potential keys to regeneration performance in mixed marginal populations, Plant Ecol., 195, 273-285, 2008.

Rosas, T., Galiano, L., Ogaya, R., Peñuelas, J., and MartínezVilalta, J.: Dynamics of non-structural carbohydrates in three Mediterranean woody species following long-term experimental drought, Front. Plant Sci., 4, 400, doi:10.3389/fpls.2013.00400, 2013

Rozas, V. and García-González, I.: Too wet for oaks? Inter-tree competition and recent persistent wetness predispose oaks to rainfall-induced dieback in Atlantic rainy forest, Global Planet. Change, 94-95, 62-71, 2012

Sairanen, I., Novák, O., Pěnčík, A., Ikeda, Y., Jones, B., Sandberg, G., and Ljung, K.: Soluble carbohydrates regulate auxin biosynthesis via PIF proteins in Arabidopsis, Plant Cell., 24, 49074916, 2012.

Sala, A. and Hoch, G.: Height-related growth declines in ponderosa pine are not due to carbon limitation, Plant Cell Environ., 32, 22-30, 2009.

Sala, A., Woodruff, D. R., and Meinzer, F. C.: Carbon dynamics in trees: feast or famine? Tree Physiol., 32, 764-775, 2012.

Salleo, S., Trifilò, P., Esposito, S., Nardini, A., and Lo Gullo, M. A.: Starch-to-sugar conversion in wood parenchyma of field-growing Laurus nobilis plants: A component of the signal pathway for embolism repair?, Funct. Plant Biol., 36, 815-825, 2009.

Salomón, R., Rodríguez-Calcerrada, J., Zafra, E., Morales-Molino, C., Rodríguez-García, A., González-Doncel, I., Oleksyn, J., Zytkowiak, R., López, R., Miranda, J. C., Gil, L. and ValbuenaCarabaña, M.: Unearthing the roots of degradation of Quercus pyrenaica coppices: A root-to-shoot imbalance caused by historical management?, Forest Ecol. Manage., 363, 200-211, 2016.
Schneider, C. A., Rasband, W. S., and Eliceiri, K. W.: NIH Image to ImageJ: 25 years of image analysis, Nat. Methods, 9, 671-675, 2012.

Skomarkova, M. V., Vaganov, E. A., Mund, M., Knohl, A., Linke, P., Boerner, A., and Schulze, E. D.: Inter-annual and seasonal variability of radial growth, wood density and carbon isotope ratios in tree rings of beech (Fagus sylvatica) growing in Germany and Italy, Trees-Struct. Funct., 20, 571-586, 2006.

Sperry, J., Nichols, K., Sullivan, J., and Eastlack, S.: Xylem embolism in ring-porous, diffuse-porous, and coniferous trees of northern Utah and interior Alaska, Ecology, 75, 1736-1752, 1994.

Stewart, J. L., Maloof, J. N., and Nemhauser, J. L.: PIF genes mediate the effect of sucrose on seedling growth dynamics, PLoS ONE, 6, 1-8, 2011.

Urli, M., Lamy, J.-B., Sin, F., Burlett, R., Delzon, S., and Porté, A. J.: The high vulnerability of Quercus robur to drought at its southern margin paves the way for Quercus ilex, Plant Ecol., 216, 177-187, 2015.

Valladares, F., Martinez-Ferri, E., Balaguer, L., Perez-Corona, E., and Manrique, E.: Low leaf-level response to light and nutrients in Mediterranean evergreen oaks: A conservative resource-use strategy?, New Phytol., 148, 79-91, 2000.

Wang, L. and Ruan Y.-L.: Regulation of cell division and expansion by sugar and auxin signaling, Front. Plant Sci., 4, 163, doi:10.3389/fpls.2013.00163, 2013. 